\title{
Video-assisted thoracoscopic tracheal tumor resection with acupuncture drug compound non-intubated anesthesia: a case report
}

\author{
Zhuoqi Jia ${ }^{1}$, Weiru Zhou ${ }^{2}$, Bingyu Liu ${ }^{3}$, Jian Wen ${ }^{3}$, Qiang Wang ${ }^{3}$, Guangjian Zhang', Junke Fu ${ }^{1}$ \\ ${ }^{1}$ Department of Thoracic Surgery, First Affiliated Hospital of Xi'an Jiaotong University, Xi'an, China; ${ }^{2}$ Department of Nuclear Medicine, Xi'an \\ Gaoxin Hospital, Xi'an, China; ${ }^{3}$ Department of Anesthesiology and Perioperative Medicine, First Affiliated Hospital of Xi'an Jiaotong University, \\ Xi'an, China \\ Correspondence to: Zhuoqi Jia, MD. Department of Thoracic Surgery, First Affiliated Hospital of Xi'an Jiaotong University, Xi'an 710061, China. \\ Email: gosnow@163.com.
}

Background: Primary tracheal tumors are very rare, surgical treatment is the first choice, and the extent
of resection and anastomosis is determined by the location, shape and size and pathological result of the
tumor. With the rapid development of minimally invasive techniques and instruments in video-assisted
thoracoscopic surgery, but tracheal surgery is usually considered to be the most challenging and complex
thoracic surgery, which requires not only extraordinary surgical skill, but also good anesthesia management
performed by anesthesiologists. Few studies have reported the safety and effectiveness of VATS resection and
reconstruction of the tracheal. Case Description: Here we report a case of 47-years female, complaining of cough and short of breath for three months. Bronchoscopy showed a tracheal neoplasm located in the lower trachea, $2 \mathrm{~cm}$ away from carina, biopsy result was adenoid cystic carcinoma,and other examinations showed no distant metastasis. After MDT discussion, our surgical team performed 3-port VATS tracheal tumor resection and end-to-end anastomosis with acupuncture drug compound non-intubated anesthesia, our anesthesia team performed spontaneous breathing anesthesia with laryngeal mask to protect the airway, closely observing and prepared for intubation in case of emergency. The patient recovered well with no complication.

Conclusion: Our initial experience of VATS tracheal tumor resection and anastomosis with acupuncture drug compound non-intubated anesthesia showed technically safe and feasible. No-intubation anesthesia would reduce damage of the tracheal and ventilator-related lung injury, and acupuncture drug stimulationassisted anesthesia would reduce the dosage of opioids, enhance recovery of patient.

Keywords: Case report; video-assisted thoracoscopic surgery (VATS); tracheal tumor; adenoid cystic carcinoma; acupuncture drug anesthesia

Received: 04 June 2021; Accepted: 18 November 2021; Published: 30 January 2022.

doi: $10.21037 /$ shc-21-12

View this article at: https://dx.doi.org/10.21037/shc-21-12

\section{Introduction}

Since Kuester's first successful tracheal operation in 1884 (1), the progress of tracheal surgery has been slow. In the past 40 years, with the development of anesthetic technology and the application of extracorporeal circulation technology, long segmental tracheotomy, tracheal bronchial sleeve resection, complex tracheal carina reconstruction, artificial tracheal replacement and allogeneic tracheal transplantation (2) have been gradually carried out. Traditionally tracheal tumor resection with open thoracic surgery is an utterly challenging procedure even for experienced surgical teams (3). Owning to the rapid development of video-assisted thoracoscopic surgery (VATS), recent studies have demonstrated that VATS 


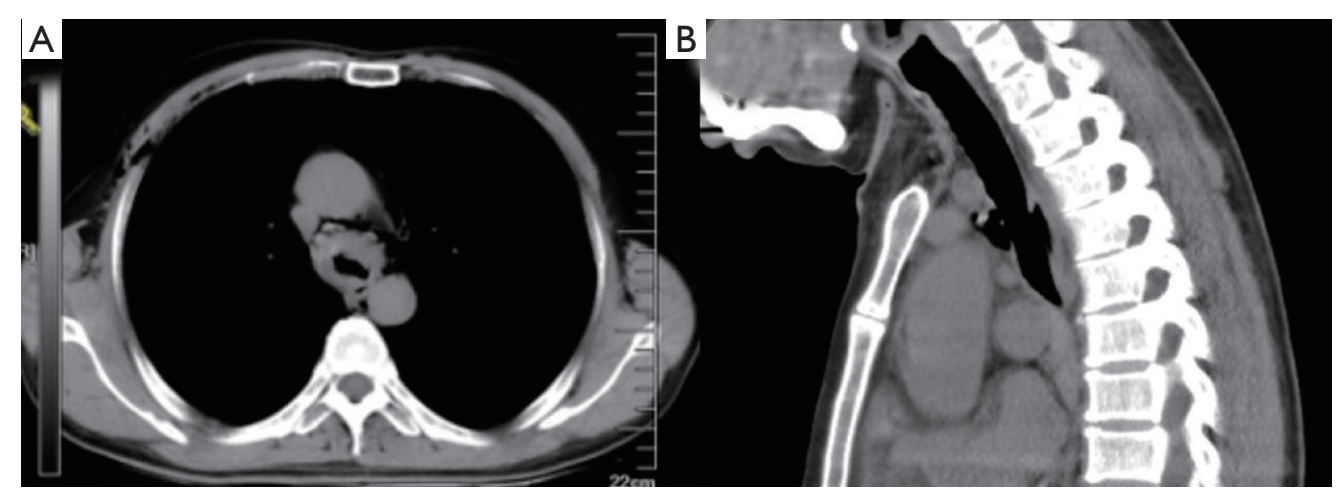

Figure 1 Chest CT before operation. (A) Tracheal wall thickened. (B) Tracheal lumen was narrow.
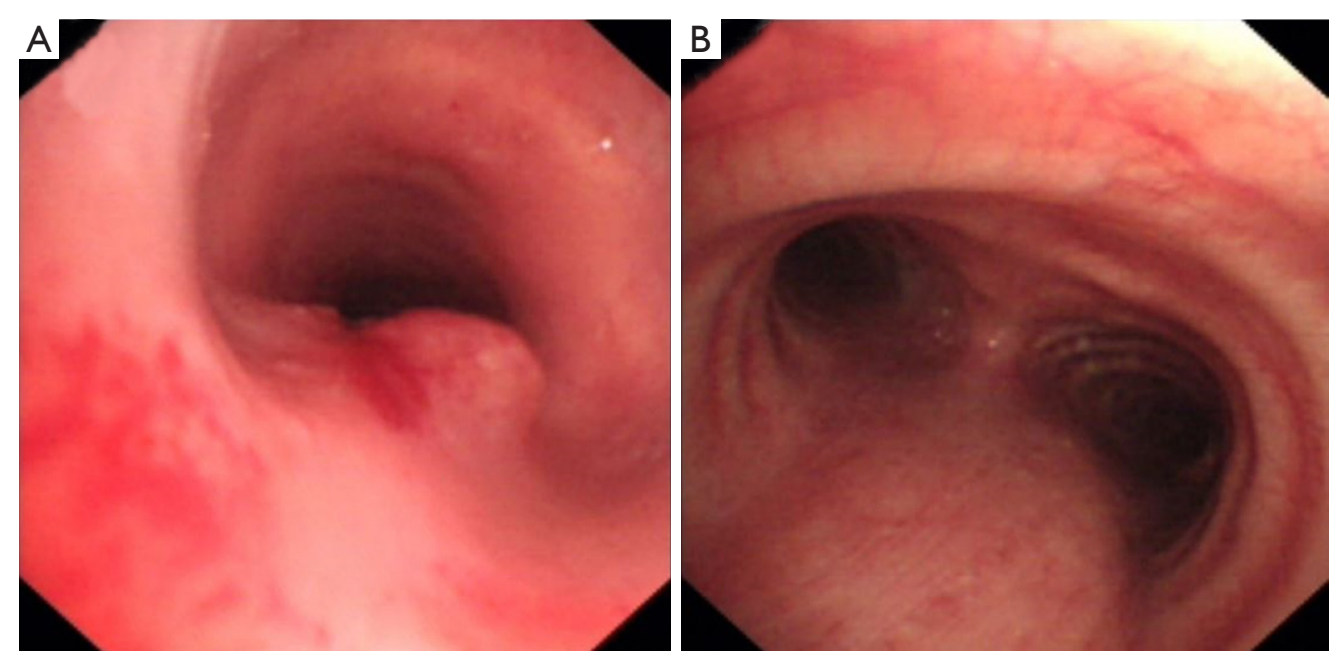

Figure 2 Bronchoscopy before operation. (A) Tracheal neoplasm mucosa was rough and congested. (B) Distant to carinal was $2 \mathrm{~cm}$.

tracheal tumor resection have the advantages of satisfactory clinical results and fewer complications, which could enhance recovery $(4,5)$. This paper presents a successful case of VATS tracheal tumor resection with acupuncture drug compound non-intubated anesthesia.

We present the following article in accordance with the CARE reporting checklist (available at https://shc. amegroups.com/article/view/10.21037/shc-21-12/rc).

\section{Case presentation}

All procedures performed in studies involving human participants were in accordance with the ethical standards of the institutional and/or national research committee(s) and with the Helsinki Declaration (as revised in 2013). Written informed consent was obtained from the patient for publication of this case report and any accompanying images. A copy of the written consent is available for review by the editorial office of this journal.

A 47-year-old female, complaining for cough and shortness of breath for 3 months. Chest computerized tomography and bronchoscope showed lower tracheal neoplasm with a narrow tracheal lumen about $2 \mathrm{~cm}$ proximal to the carina (Figures 1,2). Bronchoscopy biopsy result was adenoid cystic carcinoma, and other examinations showed no distant metastasis.

Electroacupuncture acupoint: we chose Hegu, Neiguan, Taichong, Qiu Xu and other acupuncture acupoints. Appling single-hand acupuncture method, electroacupuncture acupoint stimulator was connected, and the frequency of electroacupuncture was $2 / 100 \mathrm{~Hz}$, while the stimulation intensity was the maximum stimulation intensity so that the 

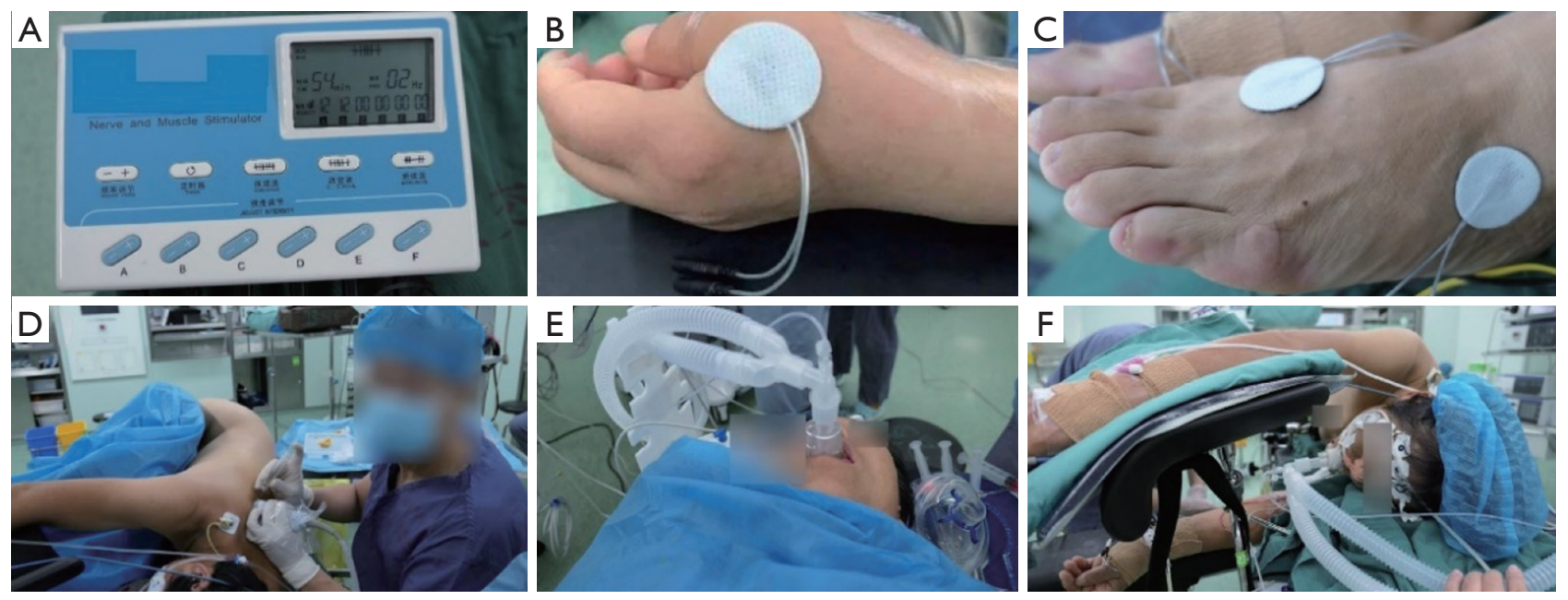

Figure 3 Acupuncture drug compound non-intubated anesthesia. (A) Electronic acupuncture apparatus. (B) Hand acupoint selection: HeGu and NeiGuan acupoint. (C) Foot acupoint selection: TaiChong and QiuXu acupoint. (D) Thoracic epidural anesthesia. (E) Laryngeal mask non-intubated spontaneous breathing anesthesia. (F) Left lateral decubitus and fold position.

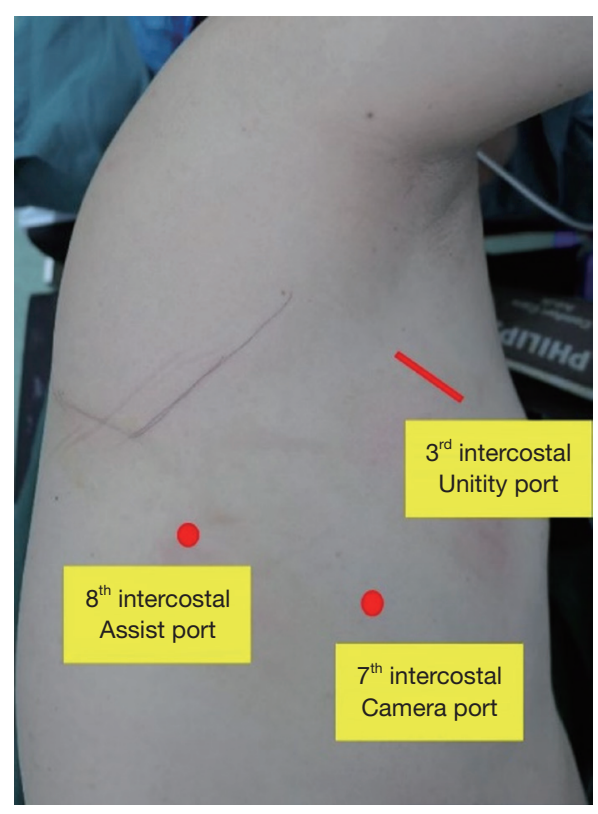

Figure 4 Patient's position and surgery ports placement.

patient could endure and it did not cause pain in conscious state. Intraoperative stimulation lasted from $30 \mathrm{~min}$ before anesthesia to the end of the operation (Figure 3A-3C).

Thoracic epidural anesthesia: after entering the operating room, the puncture point of thoracic epidural block was T3-4 (Figure 3D). Epidural catheter was placed and $2 \%$ lidocaine $2 \mathrm{~mL}$ was injected into the supine position for $5 \mathrm{~min}$; $0.375 \%$ ropivacaine $3 \mathrm{~mL}$ was injected afterwards, so that the anesthesia plane could reach the T2 T10 area. TCI propofol initial concentration $4 \mu \mathrm{g} / \mathrm{mL}$ maintenance concentration $1-3.5 \mu \mathrm{g} / \mathrm{mL}$, remifentanil $0.03-0.08 \mu \mathrm{g} / \mathrm{kg} / \mathrm{min}$, Dexmedetomidine $0.5-1 \mu \mathrm{g} / \mathrm{kg} / \mathrm{h}$. Bis (Aspect Medical Systems Inc., Norwood, MA, USA) monitor stayed 40-60 and invasive radial arterial pressure was recorded during operation. Then the patient was put on laryngeal mask (4\#, igel LMA) and connected the Ohmeda anesthesia machine (SIMV breathing mode) to maintain her autonomous breathing state and to keep the spontaneous breathing situation as well (Figure $3 E$ ). For the sake of safety, if $\mathrm{SpO}_{2}$ gradually decreased to below $90 \%$, maskassisted ventilation would be given to improve oxygenation; if $\mathrm{PaCO}_{2}$ reached or exceeded $80 \mathrm{mmHg}(1 \mathrm{mmHg}$ $=0.133 \mathrm{kPa})$, mask-assisted ventilation would be applied to meliorate gas exchange; if no improvement occurred, endotracheal intubation would be performed immediately.

The patient was placed in the left lateral decubitus and fold position (Figure $3 F$ ) and we applied the standard 3-port approach (Figure 4). There were two $10 \mathrm{~mm}$ ports, one was located in the 7 th intercostal space, midaxillary line as the camera port, the other one was at 8 th intercostal space, scapular line as assisted port. The utility port was located in the $3 \mathrm{rd}$ intercostal space, anterior axillary line, about $3.5 \mathrm{~cm}$. A plastic wound protector kept the utility wound open.

Operation: after exploration with video-assisted thoracoscopy, $5 \%$ lidocaine infiltration block was supplied 

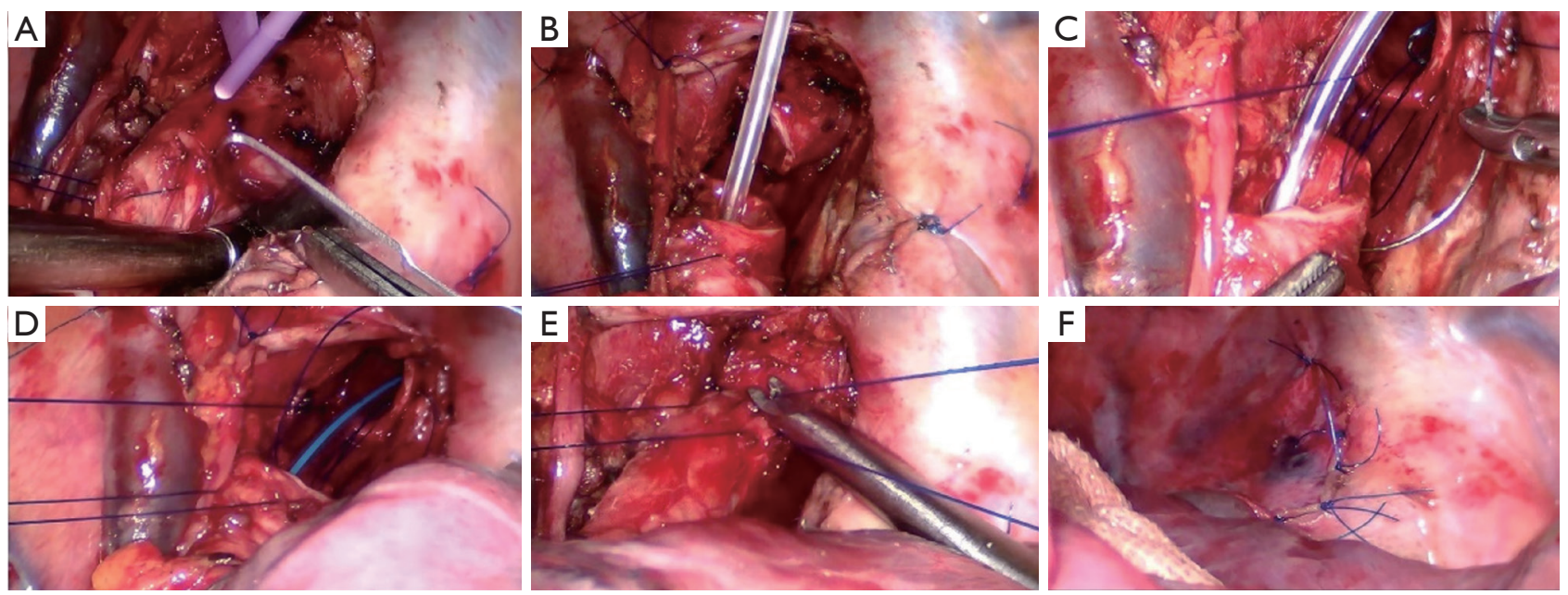

Figure 5 Tracheal tumor resection. (A) Exposure of lower edge of the tracheal tumor. (B) Exposure of the upper edge of the tracheal tumor. (C) Insertion the fine thread catheter into the lower segment of the tracheal. (D) Running suture of the tracheal stumps. (E) All knots tied externally. (F) Embedded mediastinal pleura around the anastomosis.

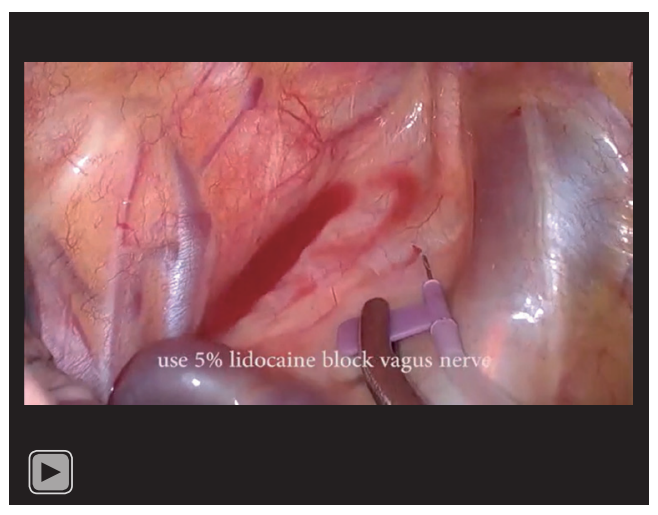

Video 1 Video-assisted thoracoscopic tracheal tumor resection with acupuncture drug compound non-intubated anesthesia.

to the vagus nerve above the azygos vein, and $2 \%$ lidocaine was sprayed on the surface of right lung to prevent cough and traction reflex.

Firstly dissecting and Endo-GIA to cut off the azygos vein arch, and then suturing the stump to the mediastinal pleura; the main trunk of the vagus nerve was separated and sutured to the mediastinal pleura for increasing the surgical field. Fully dissociating the lower segment of the tracheal and dissecting group $2 \mathrm{R}$ lymph nodes at the same time. While the left recurrent laryngeal nerve lymph nodes were dissected behind the tracheal.

Guided by bronchoscopy (BF-H290, Olympus, Tokyo, Japan), the anesthetist located the tumor boundary, and surgeon inserted a venous needle (9\# scalp needle) at the lower margin of tracheal tumor from operative port. The incision was made with $1 \mathrm{~cm}$ distance from the tumor margin (Figure $5 A$ ), and sutured the traction line. After that, an incision $1 \mathrm{~cm}$ proximal to the upper edge of the tumor was performed, thereby completely removing the tumor, and immediately inserting the fine thread catheter (14\# nasogastric tube, WGS-II-12) into the lower segment of the tracheal through the assistance port (Figure 5B), subsequently high frequency ventilation was to started to supply sufficient oxygen for the patient. The cutting margine of the tumor specimen appeared to be negative, and the result of frozen pathology showed no tumor tissue in both stumps of the tracheal (Video 1).

We used 3-0 prolene (double needles) to perform a running suture, starting from the membranous part of trachea (Figure 5C), the stiches were about $2 \mathrm{~mm}$ apart. When the tracheal ring was sutured for nearly half its part, the anesthetist inserted another fine threaded catheter through the laryngeal mask into the lower part of the trachea, applying high frequency ventilation to ensure adequate supply of oxygen (Figure 5D), while removing the previous catheter. The last part of were sutured with an anterior needle. All knots should be tied externally (Figure 5E). It is crucial that the assistant should maintain a certain tension on the knots to prevent them from loosening. In the meantime, the surgeon should pay attention to the direction of suturing and to avoid wrapping the knots. After completing the 

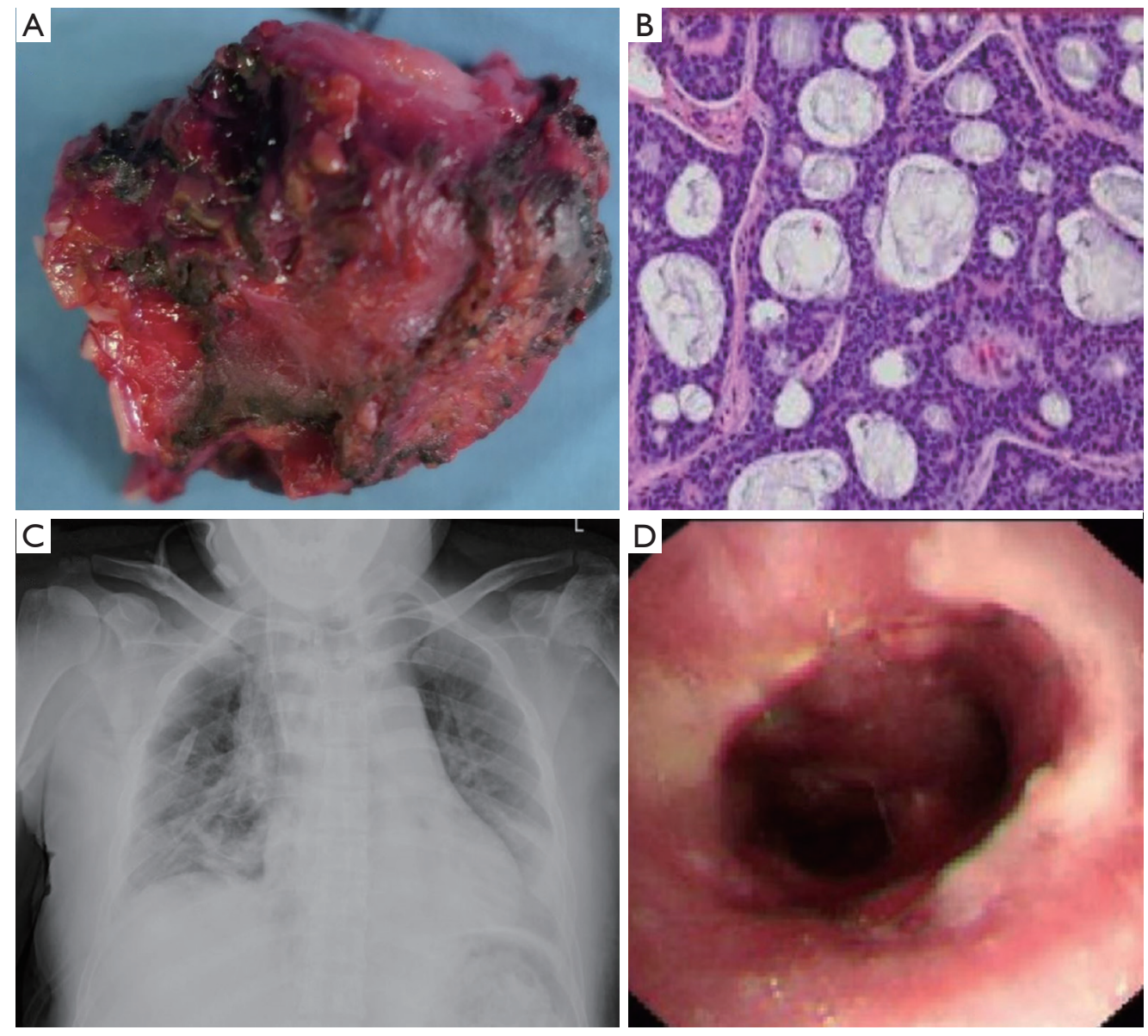

Figure 6 Pathological report and postoperation recovery. (A) Tracheal tumor specimen. (B) Pathology result: adenoid cystic carcinoma. Staining method: HE stain. Magnification: $\times 10$. (C) Chest X-ray postoperation. (D) Bronchoscopy showed the tracheal anastomosis healed well.

anastomosis, the lungs were flushed with normal saline and ventilated to inflate. No abnormal air leakage was found at the anastomotic site, and the mediastinal pleura was embedded around the area (Figure $5 F$ ). Thoracic drainage tube was placed and all incisions were sutured.

The operation time was $178 \mathrm{~min}$ and the perioperative blood loss was $85 \mathrm{~mL}$. Pathology result: adenoid cystic carcinoma invaded to outer layer of tracheal, and two stumps showed no tumor tissue; group 2R (4 lymph nodes) and left recurrent laryngeal nerve (3 lymph nodes) had no metastasis (Figure 6A,6B). The patient recovered well with no complication. Drainage tube was removed on 6th postoperative day (POD), after X-ray revealed good lung re-expansion (Figure 6C). Postoperation bronchoscopy revealed tracheal anastomosis healed well (Figure 6D).

\section{Discussion}

Whether benign or malignant tracheal tumors, surgical resection and removal of respiratory obstruction is the first choice for treatment (6). R0 resection means negative margin, which is the critical prognostic factor for long-term survival of patients with tracheal tumors (7). Thoracotomy can provide a good visual field and has always been the standard surgical approach for tracheal surgery. When tumor is located in the middle or upper segment of the trachea, the cervical incision or auxiliary semi-split sternal incision can be applied; when lesion is located in the lower segment of the trachea or main bronchus, the 4th or 5th intercostal chest incision can be selected. Segmental tracheal resection and end-to-end anastomosis are ideal procedures for treatment of tracheal tumors (8). The length of tracheal 
resection should be controlled between 2 to $4 \mathrm{~cm}$, for purpose of reducing the tension of the anastomosis (9).

With the advances in VATS minimally invasive techniques and devices, some studies have indicated VATS lobectomy, pneumonectomy and segmentectomy have less pain and lower complication rate compared with open surgery $(10,11)$. However, tracheal surgery is usually considered to be the most challenging and complex thoracic surgery with high risk, which requires not only extraordinary surgical skills, but also good anesthesiological and satisfactory ventilation performed by anesthesiologists. Only few cases have reported VATS tracheal resection and reconstruction (12-15).

After nearly 20 years of evolution, the concept of minimally invasive thoracic surgery has been greatly accepted by most surgeons all over the world, yet how to develop the more minimally invasive methods including new anesthetic techniques has become one of the main topics of thoracic surgery research. Double-lumen endotracheal intubation anesthesia not only ensures the demand of pulmonary ventilation, but also has a positive impact of pulmonary isolation. Nevertheless, intubation can cause some typical problems such as bronchospasm, pulmonary infection, ventilated lung injury, arrhythmia, postoperative sore throat and irritant cough (16). In 2004, Pompeo et al. (17) reported the first case of VATS lung nodule wedge resection with non-intubation anesthesia. Since then, a series of studies have reported the feasibility and safety of non-intubation thoracoscopic surgery (NITS). Spontaneous breathing and non-intubation anesthesia would avoid most symptoms and meet the requirements of clinical thoracic surgeons and patients for selected cases (18). The surgical field exposure and anesthetic effects were satisfactory, greatly reducing the invasive damage of the trachea and ventilator-related lung injury. With the progress of anesthesia technology and intraoperative risk management, non-intubation anesthesia has been used in some cases of tracheal tumor resection or complex carinal reconstruction (19-21).

Acupuncture anesthesia is a significant breakthrough in the history of traditional Chinese medicine. Certain studies have reported acupuncture drug stimulationassisted anesthesia can reduce the dosage of opioids, while minimizing the occurrence of adverse reactions such as respiratory inhibition, nausea and vomiting, constipation and urinary retention, decreasing tissue oxidative stress injury and production of inflammatory factors, regulating the immune function of the body, achieving the protective effect of heart, brain and other vital organs, shortening the time of tracheal intubation and promote postoperative recovery (22). It has become an essential medical method in perioperative period. The principle of acupoint selection is mainly local acupoint selection, distal acupoint selection and empirical acupoint selection.

Our multidisciplinary team discussed the patient's medical history and tumor situation based on our experience of VATS tracheal resection and complex reconstruction, acupuncture compound non-intubated anesthesia VATS lobectomy and segmentectomy in recent years, and then decided to perform VATS tracheal resection and endto-end anastomosis with acupuncture drug compound non-intubated anesthesia, which is more complex, more challenging with less injury and faster recovery. After satisfactory electroacupuncture of acupoints and thoracic epidural anesthesia, our anesthesia team performed spontaneous breathing anesthesia with laryngeal mask to protect the airway, closely observing and prepared for intubation in case of emergency. Three key points were revealed: (I) without endotracheal intubation, the vision of operation field was clearer, the resection and anastomosis would be more flexible and faster, while the operation time was shorter. (II) The successful cooperation between surgeons and anesthetists was the crux of this challenging operation, which was especially reflected in the process when surgeons completely removed the tumor, anesthetists immediately inserted another fine thread catheter from laryngeal mask into the lower segment of the tracheal to maintain sufficient oxygenation. (III) During the anastomosis, 3-0 or 4-0 prolene was applied to perform running suture, and the assistant must tighten the knots continuously and maintain a proper tension to prevent the knots from loosening or entangling.

\section{Conclusions}

Primary tracheal tumor is rare in clinic, which has commonly unspecific symptoms and signs in early stage, and the diagnosis mainly depends on bronchoscopy and chest examination. The principle of treatment is to remove the tumor as much as possible to relieve the symptoms of respiratory obstruction. Surgical treatment is effective for early-stage patients, and endotracheal interventional therapy by bronchoscopy combined with chemotherapy and radiotherapy is efficacious for later stage patients. Our case of video-assisted thoracoscopic tracheal tumor resection with acupuncture drug compound non-intubated anesthesia is technically safe and feasible, and has certain advantages 
for the rehabilitation of patients. Studies with larger cohorts should be conducted in the future to demonstrate the benefits of this procedure on long-term survival.

\section{Acknowledgments}

Funding: Institutional Foundation of The First Hospital of Xi'an Jiaotong University (No. 2020ZYTS-21).

\section{Footnote}

Reporting Checklist: The authors have completed the CARE reporting checklist. Available at https://shc.amegroups.com/ article/view/10.21037/shc-21-12/rc

Peer Review File: Available at https://shc.amegroups.com/ article/view/10.21037/shc-21-12/prf

Conflicts of Interest: All authors have completed the ICMJE uniform disclosure form (available at https://shc.amegroups. com/article/view/10.21037/shc-21-12/coif). The authors have no conflicts of interest to declare.

Ethical Statement: The authors are accountable for all aspects of the work in ensuring that questions related to the accuracy or integrity of any part of the work are appropriately investigated and resolved. All procedures performed in studies involving human participants were in accordance with the ethical standards of the institutional and/or national research committee(s) and with the Helsinki Declaration (as revised in 2013). Written informed consent was obtained from the patient for publication of this case report and any accompanying images. A copy of the written consent is available for review by the editorial office of this journal.

Open Access Statement: This is an Open Access article distributed in accordance with the Creative Commons Attribution-NonCommercial-NoDerivs 4.0 International License (CC BY-NC-ND 4.0), which permits the noncommercial replication and distribution of the article with the strict proviso that no changes or edits are made and the original work is properly cited (including links to both the formal publication through the relevant DOI and the license). See: https://creativecommons.org/licenses/by-nc-nd/4.0/.

\section{References}

1. Pearson FG, Cooper JD, Deslauriers J. Thoracic Surgery. second edition. Amsterdam: Elsevier, 2002:1005-13.

2. Etienne H, Fabre D, Gomez Caro A, et al. Tracheal replacement. Eur Respir J 2018;51:1702211.

3. Diaz-Mendoza J, Debiane L, Peralta AR, et al. Tracheal tumors. Curr Opin Pulm Med 2019;25:336-43.

4. Li S, Liu J, He J, et al. Video-assisted thoracoscopic surgery resection and reconstruction of thoracic trachea in the management of a tracheal neoplasm. J Thorac Dis 2016;8:600-7.

5. Yang H, Yao F, Tantai J, et al. Resected Tracheal Adenoid Cystic Carcinoma: Improvements in Outcome at a Single Institution. Ann Thorac Surg 2016;101:294-300.

6. D'Andrilli A, Rendina EA, Venuta F. Tracheal surgery. Monaldi Arch Chest Dis 2010;73:105-15.

7. Madariaga MLL, Gaissert HA. Overview of malignant tracheal tumors. Ann Cardiothorac Surg 2018;7:244-54.

8. Behringer D, Könemann S, Hecker E. Treatment approaches to primary tracheal cancer. Thorac Surg Clin 2014;24:73-6.

9. Macchiarini P. Primary tracheal tumours. Lancet Oncol 2006;7:83-91.

10. Mehta H, Osasona A, Shan Y, et al. Trends and Outcomes of Thoracoscopic Lobectomy or Segmentectomy: A National Surgical Quality Improvement Project Analysis. Semin Thorac Cardiovasc Surg 2018;30:350-9.

11. Yang HX, Woo KM, Sima CS, et al. Long-term Survival Based on the Surgical Approach to Lobectomy For Clinical Stage I Nonsmall Cell Lung Cancer: Comparison of Robotic, Video-assisted Thoracic Surgery, and Thoracotomy Lobectomy. Ann Surg 2017;265:431-7.

12. He J, Wang W, Li J, et al. Video-assisted thoracoscopic surgery tracheal resection and carinal reconstruction for tracheal adenoid cystic carcinoma. J Thorac Dis 2016;8:198-203.

13. Gonzalez-Rivas D, Soultanis KM, Garcia A, et al. Uniportal video-assisted thoracoscopic lung sparing tracheo-bronchial and carinal sleeve resections. J Thorac Dis 2020;12:6198-209.

14. Hung WH, Chen HC, Huang CL, et al. Thoracoscopic Tracheal Resection and Reconstruction With SingleIncision Method. Ann Thorac Surg 2018;106:e45-7.

15. Imanishi $\mathrm{N}$, Tanaka $\mathrm{F}$. Thoracoscopic tracheal resection and reconstruction: video-assisted thoracoscopic surgery as a "tool" toward minimally invasive surgery. J Thorac Dis 2017;9:2895-7.

16. Gonzalez-Rivas D, Bonome C, Fieira E, et al. Nonintubated video-assisted thoracoscopic lung resections: the future of thoracic surgery? Eur J Cardiothorac Surg 
2016;49:721-31.

17. Pompeo E, Mineo D, Rogliani P, et al. Feasibility and results of awake thoracoscopic resection of solitary pulmonary nodules. Ann Thorac Surg 2004;78:1761-8.

18. Hung WT, Hung MH, Wang ML, et al. Nonintubated Thoracoscopic Surgery for Lung Tumor: Seven Years' Experience With 1,025 Patients. Ann Thorac Surg 2019; 107:1607-12.

19. Jiang L, Liu J, Gonzalez-Rivas D, et al. Thoracoscopic surgery for tracheal and carinal resection and reconstruction under spontaneous ventilation. J Thorac Cardiovasc Surg 2018;155:2746-54.

doi: $10.21037 /$ shc-21-12

Cite this article as: Jia Z, Zhou W, Liu B, Wen J, Wang Q, Zhang G, Fu J. Video-assisted thoracoscopic tracheal tumor resection with acupuncture drug compound non-intubated anesthesia: a case report. Shanghai Chest 2022;6:10.
20. Zhao K, Mei J, Hai Y, et al. Thoracoscopic tracheal reconstruction without surgical field intubation. Thorac Cancer 2016;7:495-7.

21. Zhou Y, Liu H, Wu X, et al. Spontaneous breathing anesthesia for cervical tracheal resection and reconstruction. J Thorac Dis 2019;11:5336-42.

22. Chinese society of anesthesiology task force on perioperative application of acupoint stimulation. Consensus on perioperative application of acupoint stimulation. Chinese Journal of Anesthesiology 2017;37:1153-8. 